\title{
Welcome Address
}

\section{ULRICH FÖRSTERMANN, VICE-PRESIDENT FOR RESEARCH, Johannes Gutenberg-University, MaInZ}

This volume presents the papers of the International Conference on Cultural History in Europe, which took place in Mainz from March $17^{\text {th }}$ till $21^{\text {st }} 2010$. It was the first international conference of the Collaborative Research Focus on Historical Cultural Sciences of the Johannes Gutenberg University.

This Research Focus investigates the distinctive nature of cultural circumstances within their respective individual historical context. It is one of the seven Research Foci of our University, which were selected in a competitive process for their specific potential for interdisciplinary research. The selection occurred with external expertise under the auspices of our very own Gutenberg Research College. Financially supported by the State of Rhineland-Palatinate from 2008 to 2013, the Research Focus Historical Cultural Sciences aims at developing a specific historical-cultural profile within the University's general academic portfolio.

Please, allow me to explain this concept: The Research Focus combines several departments and different academic disciplines within our University, thereby interconnecting and stimulating research within the cultural sciences. The Focus combines empirical work and profound theoretical and methodological considerations in a historical perspective.

Overall, the internationally competitive research at the Johannes Gutenberg University is characterized by a broad variety of disciplines. As an international research location, we resolutely pursue a strategy of promoting excellence in science and the Humanities, hosting eight Collaborative Research Centers, ten Research Groups, and eight Graduate Schools (all funded by the German Research Foundation), as well as numerous research initiatives funded by other sources, both public and private.

The conference and this subsequent volume is a prime example for the successful efforts of our scholars and their efficient international cooperation 
with other research groups. It intends to comprehensively take stock of cultural history in Europe: Participants from over ten European countries will:

- report on the state of cultural history in their respective countries,

- consider in which way cultural history, as an academic discipline, is incorporated into the structured system of their own Universities, research institutes or other institutions,

- ascertain which questions and topics are particularly in demand in certain countries or have already been dealt with to a large extent,

- identify (presumed) future fields of research,

- examine the opportunities and the limits of financial support from Universities and/or (state) governments, and

- consider the relationship of cultural history to other parts of historical science and to cultural studies in a wider sense.

Historical Cultural Sciences have a long tradition at our University - not only in the social sciences but in all of the humanities - a special research library is currently being established on our campus. Furthermore, our colleagues invited several outstanding scholars in the field of Theories and Methods of Historical Cultural Sciences to Mainz as Fellows of our Gutenberg Research College. In this context, they also:

- organize interdisciplinary research symposia three to four times each semester in order to increase synergies between the different academic disciplines,

- publish a new historical-cultural book series called Mainzer Historische Kulturwissenschaften (Mainz Historical Cultural Sciences), the first four volumes are already published, and

- initiate a project to develop a manual on key concepts of the Historical Cultural Sciences.

In short, Historical Cultural Sciences here in Mainz are pursuing a path of excellence, which, we hope, will eventually also be acknowledged in the upcoming Federal Excellence Initiative.

By bringing together young and established scholars from all over the world, this conference was a shining example for the way our University actively participates in the global academic community and contributes to our overall goal of continuing internationalization of academic programs and research. Our University gains much from such exchanges, and we greatly appreciate the contacts we have been able to make and maintain.

Let me say "thank you" to the many supporters and organizers: First and foremost Jörg Rogge and his team, who have done a wonderful job in organizing 
the conference and editing this volume. They received considerable help, I hear, by our colleagues from the Medieval section of our Department of History. Last but not least I would like to thank the German Research Foundation (DFG) for their generous support of the conference. 
